\title{
Driving service innovativeness via collaboration with customers and suppliers: \\ Evidence from business-to-business services
}

\begin{abstract}
Service innovativeness represents a key source of competitive advantage and a research priority. However, empirical evidence about how service firms successfully offer novel and meaningful services is scarce, particularly in the context of business-to-business (B2B) service firms. Drawing on the B2B collaborative perspective and KBV, we aim to investigate when customer and supplier collaboration are more beneficial to drive service novelty and meaningfulness. Using data of 186 B2B service firms, the results reveal that collaboration with customers and suppliers are not equally beneficial to drive both novelty and meaningfulness and their outcomes can be amplified or lost under specific conditions. Customer collaboration is more beneficial to increase novelty in the presence of exploratory learning and employee collaboration. Contrary, supplier collaboration drives novelty only at higher levels of exploratory learning. Further, supplier collaboration is more beneficial to improve meaningfulness at higher levels of employee collaboration. Finally, the positive outcomes of both customer and supplier collaboration disappear in the presence of knowledge tacitness. Our findings provide new insights about drivers and contingencies that affect different aspects of service innovativeness.
\end{abstract}

Keywords: Service innovativeness; customer collaboration; supplier collaboration; exploratory learning; cross-functional collaboration; knowledge tacitness 


\section{Introduction}

Offering novel and meaningful services are critically important in business-to-business (B2B) service firms to face the growing competition and dynamism of their business environment (Chen et al., 2011; Dotzel et al., 2013). B2B service firms not only have to compete by elevating the novelty and uniqueness of their services, but also by offering services that are useful for business customers and effectively address their needs (Ordanini et al., 2014; Stock et al., 2015). Novelty and meaningfulness are conceptually distinct aspects of service innovativeness that together explain how successful new or enhanced services offer unique and meaningful benefits to customers over existing services in the market (Ordanini et al., 2014). Despite the growing attention to service innovativeness, the current literature is mainly focused on the drivers of different degrees of novelty or newness (e.g., radical vs incremental in Chen et al., 2011; Ordanini \& Parasuraman, 2011; Snyder et al., 2016). Little is known about distinct drivers of service novelty and meaningfulness, particularly in the B2B services context.

Although the provision of novel and meaningful services is critical, no single service firm possesses all knowledge and competences to succeed by itself (Chen et al., 2011; Baker et al., 2016). To overcome these constraints, many service firms look outside of their boundaries and collaborate with business partners (Carbonell et al., 2009; Baker et al., 2016). The literature views customers and suppliers as key external resources, and building effective collaboration with them represents a valuable and inimitable source of competitive advantage (Agarwal \& Selen, 2009; Ordanini \& Parasuraman, 2011). Despite the growing importance of interfirm collaboration in $\mathrm{B} 2 \mathrm{~B}$ services, the current literature is limited to investigating the direct contributions of customer and supplier collaboration on the market outcomes and financial performance (e.g., Carbonell et al., 2009; Melton \& Hartline, 2010). Yet, little is known whether collaboration with customers and suppliers are equally beneficial to drive both service novelty and meaningfulness. Furthermore, it is acknowledged that firms should possess 
specific organizational mechanisms to utilize external knowledge shared by business partners (Agrawal \& Selen, 2009; Mina et al., 2014). However, we still lack understanding of how specific knowledge management mechanisms may amplify or impede the outcomes of customer and supplier collaboration in terms of service novelty and meaningfulness.

Building on B2B collaborative perspective (Agarwal \& Selen, 2009; Mina et al., 2014) and knowledge-based view (KBV) of the firm (Grant, 1996), we aim to advance the understanding of the different effects of collaboration with business partners on service novelty and meaningfulness in the context of B2B services. B2B collaborative perspective explains the extent that service firms benefit from interfirm collaboration to successfully develop innovative services (Agrawal \& Selen, 2009). KBV provide insights about the specific organizational mechanisms that are required to manage and utilize knowledge within the firm (Grant, 1996; Melton \& Hartline, 2012). Although collaboration with customers and suppliers help B2B service firms possess the external knowledge, identification of knowledge management factors that impede or facilitate the acquisition, integration, and utilization of external knowledge is equally important (Rothaermel \& Alexandre 2009; Ordanini \& Parasuraman, 2011). Following recommendations by Stewart and Zinkhan (2006) and Ostrom et al. (2015), we integrate KBV and collaborative perspective to develop a framework to investigate the independent roles of customer and supplier collaboration and how specific knowledge management factors help B2B service firms to successfully drive novelty and meaningfulness of their services.

Our study provides two contributions to the literature. First, we extend the work of Ordanini and Parasuraman (2011) who examined the drivers of service innovation outcomes (couched as radicalness and volume) by investigating the independent effects of customer and supplier collaboration on both service novelty and meaningfulness. We respond to the call by Ostrom et al. (2015) who suggest service innovation in complex service network as a key research priority. We argue that while novelty and meaningfulness are overarching aspects of 
service innovativeness, collaboration with different partners in the service network may affect them differently (Kim et al., 2013; Stock et al., 2015). Therefore, B2B service firms need to understand which form of collaboration is beneficial to drive service novelty and meaningfulness. We contribute to the B2B services literature by showing that collaboration with customers and suppliers are not always beneficial to drive both service novelty and meaningfulness.

Second, we investigate the role of knowledge management mechanisms and the nature of B2B service firm's knowledge to understand the condition that may influence the impact of customer and supplier collaboration on service novelty and meaningfulness. The current KBV literature has identified organizational learning activities (Melton \& Hartline, 2013; Mazloomi et al., 2017), cross-functional collaboration (Ordanini \& Parasuraman, 2011), and knowledge tacitness (Kim et al., 2013) as the key factors that influence the knowledge management. The current literature acknowledges that different organizational learning activities influence the firm's behavior when collaborating with business partners. Literature supports the view that exploitative learning drives firms to focus on the refinement of existing knowledge rather than the adoption of alternative ideas through collaboration (Rothaermel \& Deeds, 2004). Exploratory learning pushes firms to acquire new knowledge beyond their boundaries and leverage interfirm collaboration to explore new knowledge domains (Rothaermel \& Deeds, 2004). It is advocated that firms should foster their knowledge base diversity and learn knowledge beyond existing boundaries to successfully innovate novel services that address customer needs better than existing services (Perks et al., 2012; Mazloomi et al., 2017). The more a firm is exploratory oriented, the more is likely to acquire and utilize diverse knowledge from its business partners (Mazloomi et al., 2017). Thus, we investigate the contextual effect of exploratory learning on the outcomes of customers and suppliers collaboration with respect to service novelty and meaningfulness. 
We also focus on the contextual role of cross-functional collaboration (CFC) as the key organizational knowledge integration mechanism that facilitates analyzing, synthesizing, and applying external knowledge acquired from business partners effectively to develop and deliver innovative services (Ordanini \& Parasuraman, 2011). Further, many studies show that the tacit nature of knowledge can impede communication and knowledge sharing within interfirm collaborations (Brivot, 2011; Kim et al., 2013). The challenges associated with knowledge tacitness is specifically evident in B2B services because of the high level of expertise and tacit knowledge involved in developing and delivery of these services (Bello et al., 2016; Storey et al., 2016). Through examining the contextual roles of exploratory learning, CFC, and knowledge tacitness, we contribute to the literature and practice by identifying boundary conditions that impede or enhance the effects of customer and supplier collaboration on service novelty and meaningfulness.

\section{Conceptual background}

\subsection{Service innovativeness}

Schumpeter (1934) defines innovation as an activity through which creative ideas are turned into the marketable offerings that create profit for the firm. In Schumpeter's (1934) view, innovation refers to combining different knowledge elements to introduce new offerings that address customers' needs. In this view, newness or novelty is the central concept to measure the degree of difference between new and existing products/services to either a firm or a market (Garcia \& Calantone, 2002; Stock \& Zacharias, 2013). The extant innovation literature views the concept of newness as the indicator of a product/service innovativeness across two continuums of radical and incremental innovation (Garcia \& Calantone, 2002; Perks et al., 2012). Incremental innovation or the lower degree of newness refers to the improvement and upgrading of existing products/services (Garcia \& Calantone, 2002). Radical innovation or the 
higher degree of novelty reflects a discontinuous type of innovation that has the potential to induce new demand and shift the market structure (Perks et al., 2012; Stock \& Zacharias, 2013).

Despite the extensive attention on drivers and outcomes of incremental and radical innovation, many studies argue that the degree of newness does not solely explain why some innovative products/services are more successful compared to others in addressing customer needs (Stock \& Zacharias, 2013). In particular, services that fail to offer meaningful benefits to customers will lose the ground to competing services that already satisfy their needs (Ordanini et al., 2014). This stream of research views novelty and meaningfulness as distinct components of innovativeness (Stock \& Zacharias, 2013). While novelty reflects the originality, newness, and uniqueness of ideas; meaningfulness concerns with the appropriateness, usefulness, and advantage of the generated ideas to the target customers (Stock \& Zacharias, 2013; Ordanini et al., 2014). Consistent with this stream of research, we argue the definition of service innovativeness should capture both newness and meaningfulness. Therefore, we define service innovativeness as the extent to which a new or an enhanced service offers novel and meaningful benefits to customers compared to those available in the market (see also Bello et al., 2016; Dotzel et al., 2013).

\subsection{Interfirm collaboration}

Although innovativeness has been commonly seen as the outcomes of the firm's internal activities (Toivonen \& Tuominen, 2009), recent advances in the literature support the collaborative nature of the service development and delivery (Perks et al., 2012; Melton \& Hartline, 2013; Storey et al., 2016). This stream of research suggests that service innovativeness is the outcome of collaborative efforts of the service firm and its network of partners such as customers and suppliers (Baker et al., 2016; Perks et al., 2012). Partners contribute to idea creation, turning ideas into innovative services, and accelerating the flow of information and resources to foster innovation (Mina et al., 2014). When service firms engage 
in such collaborative relationship, they are in a better position to develop services that offer extra value to customers (Storey et al., 2016). Such views have been supported by industry reports showing approximately $26 \%$ of firms engage in specific forms of collaboration with other entities (suppliers, customers, research institutes, and competitors) to support their innovation activities (Baker et al., 2016; EUROSTAT, 2008).

B2B service firms (e.g., engineering consulting, financial consulting) are characterized as knowledge-intensive organizations, where the ability to use and transform knowledge into innovative services is the key to explain their performance variations (Dotzel et al., 2013; Bello et al., 2016). Recent advances in industrial marketing literature suggest that both customers and suppliers are important sources of external knowledge to foster innovation (Menguc et al., 2014; Ordanini \& Parasuraman, 2011). External collaboration fosters learning as service firms receive feedback and information from external collaborators enabling them to explore innovation opportunities (Baker et al., 2016; Menguc et al., 2014). Further, collaboration helps firms to understand what customers appreciate most because customers' complex needs are sticky and transferring them to firms is difficult and costly (Perks et al., 2012). Such arguments are supported by industry reports on many unsuccessful business services (e.g., Avon's $\$ 125$ million SAP ERP project in 2013), where a firm failed to engage with either customer or supplier and match the services to customer needs.

Although there is an increasing attention on the benefits of involving customers and suppliers in the new services/products development, there is evidence that collaboration with customers and suppliers can lead to different outcomes (e.g., Ordanini \& Parasuraman, 2011; Zaefarian et al., 2013). These studies provide insight about factors such as environmental conditions and formal/informal coordination mechanisms that influence the effectiveness of interfirm collaboration (Zaefarian et al., 2013; Heirati et al., 2016). Although these environmental inter-relational factors explain contingent benefits of a specific form of 
collaboration, the review of current literature offers a limited knowledge about when and under which conditions collaboration with customers and suppliers is more beneficial to successfully develop and deliver innovative services.

\subsection{Knowledge management and learning mechanisms}

The current KBV and service innovation literature posit that specific learning and knowledge integration mechanisms are required to gather, assimilate, and utilize relevant knowledge from outside of the firm to successfully develop and deliver innovative services (Ordanini \& Parasuraman, 2011; Melton \& Hartline, 2012). The organizational learning literature shows firms may engage in diverse learning activities, namely exploitative and exploratory learning (March, 1991; Mazloomi et al., 2017). Exploratory learning involves collecting and using information that are new to the firm for the purpose of experimentation and creation of new processes and service ideas, whereas exploitative learning involves collecting and using information within a limited product/market solution domain closely related to the firm's previous experience (Wang et al., 2016; Mazloomi et al., 2017). Although both exploratory and exploitative learning appears to be essential, these learning activities are fundamentally incompatible as they have different focuses and compete for scarce organizational resources (Mazloomi et al., 2017). Consequently, the trade-off between exploitative and exploratory learning is unavoidable to accommodate organizational resource constraints (Voss \& Voss, 2013). This argument is applicable to B2B service firms that are commonly small and medium sized with limited resources (Kaiser \& Ringlstetter, 2010).

We argue that B2B service firms may trade-off between different learning activities and emphasize more on exploratory learning when collaborating with business partners to develop innovative services for two reasons. First, exploratory learning drives firms to acquire diverse skills and alternative ideas beyond the current knowledge boundaries when collaborating with their partners (Rothaermel \& Deeds, 2004; Mazloomi et al., 2017). However, exploitative 
learning reflects the firm's tendency to focus on refining current knowledge rather than adopting alternative perspectives (Mazloomi et al., 2017). Given that customers and suppliers often share knowledge that differ from the ones exist inside a service firm (Franke et al., 2010), exploitative learning may stifle absorbing diverse knowledge from customers and suppliers (Mazloomi et al., 2017). Second, we adopt the premise that the intensifying competition and emergence of new technologies (e.g., data-driven and cloud-based services) drive many service firms to adapt to market changes by developing new services that address emerging market needs (Perks et al., 2012; Huang \& Rust; 2013). Innovating new services forces firms to learn new knowledge and explore emerging technologies through collaboration with their business partners (Perks et al., 2012; Mazloomi et al., 2017). Thus, we argue B2B service firms that pursue exploratory learning are more likely to learn diverse knowledge from their partners to foster adaptability and innovativeness.

Furthermore, firms should also develop knowledge integration mechanisms to effectively integrate and utilize external knowledge (Grant, 1996; Un \& Asakawa, 2015). This argument is supported by the fact that not all employees within firm directly interact with a customer or a supplier (Melton \& Hartline, 2013), and external knowledge might be imperfectly disseminated within the firm (Un \& Asakawa, 2015). CFC facilitates knowledge sharing among employees and linking relevant knowledge elements to create innovative ideas to address customer needs (Melton \& Hartline, 2013). The extant empirical studies support this argument by showing CFC helps service firms develop innovative new services (Ordanini \& Parasuraman, 2011) and drive new services' market success (Melton \& Hartline, 2013).

\subsection{Knowledge in B2B service firms}

The current KBV literature categorizes knowledge into explicit knowledge or know-that and tacit knowledge or know-how (Richtner et al., 2014). Explicit knowledge is defined as easily codifiable knowledge that can be expressed and communicated through written 
documents (e.g., reports, blueprints). By comparison, tacit knowledge is based on personal experiences and intuitions, which are sticky, complex, difficult to codify in written documents (Richtner et al., 2014). Building on the concepts of explicit and tacit knowledge, scholars categorize services into explicit and tacit services (Storey \& Kahn, 2010; Storey et al., 2016). Explicit services are delivered through standardized processes and technology means (e.g., banking service), while tacit services are delivered through interpersonal interaction (Storey \& Kahn, 2010). Delivery of tacit services such as B2B consultancy services depends on the tacit knowledge held by the service employees and are produced and consumed by customers simultaneously (Storey et al. 2016). As the level of complexity of services increases, the level of knowledge tacitness increases (Storey et al. 2016). Tacit knowledge is seen as a valuable source of competitive advantage because it is idiosyncratic, scarce, and difficult to replicate (Grant 1991). However, the key challenge arising from knowledge tacitness is how to manage and share it across employees within a firm and across business partners.

\section{Hypotheses}

We develop a theoretical framework (Figure 1) to examine the independent effects of customer and supplier collaboration on service novelty and meaningfulness, and investigate the conditions under which a specific type of collaboration is the most beneficial. We argue that collaboration with customers and suppliers have distinct effects on service novelty and meaningfulness, and the value of these effects is contingent on the levels of exploratory learning, $\mathrm{CFC}$, and knowledge tacitness.

-Figure 1 here-

\subsection{The effects of customer and supplier collaboration}


Customer collaboration represents the extent to which a B2B service firm engages with its customer to jointly develop and deliver services (Ordanini \& Parasuraman, 2011). The importance of the interactions with customers or co-creating the service with customers is widely acknowledged in the services marketing literature (Alam, 2002; Melton \& Hartline, 2010; Siahtiri, 2017). Recent studies view customers as the key source of external knowledge about their needs and new ideas (Mina et al., 2014; Ordanini \& Parasuraman, 2011). Although many firms traditionally acquire customer intelligence through market research techniques, these techniques are limited in building trust and motivating customers to reveal their hidden needs and confidential information (Blazevic \& Lievens, 2008). Customer collaboration turns a customer from a passive user to an active participant, facilitates knowledge sharing, and turns service innovation into a joint problem-solving process (Ordanini \& Parasuraman, 2011). In the context of B2B services, many business customers work with a service firm who possess the expertise to solve their unique and complex business problems (Bello et al., 2016). In this sense, both the customer and the service firm integrate their knowledge and transform the potential ideas into feasible services (Stock et al., 2015). Customers can often share creative ideas and insights that add extra value to the idea generated inside the firm (Franke et al., 2010). Through collaboration, firms and customers exchange and assimilate their knowledge to create novel service ideas (Mahr et al., 2014). Consequently, knowledge gathered from customers becomes a key resource that helps service firms to foster its own knowledge-base diversity and discover unique and novel service ideas (Alam, 2002; Mahr et al., 2014). Thus,

H1a: Customer collaboration is positively related to service novelty.

Further, customers possess relevant knowledge about their needs and willingness to share the relevant knowledge with the service provider to meet their expectations (Carbonell et al., 2009; Mahr et al., 2014). Given the complexity of business customer needs (Prior, 2013), translating innovative ideas into services that provide meaningful benefits to customers 
requires the deep understanding of customer needs. When customers collaborate, the service firm can directly communicate with customers and obtain the relevant knowledge about their needs and expectations (Baker et al., 2016). As a result, customer collaboration will help service firms to identify customers' explicit and implicit needs, and better align the service specifications to customer's requirements. Through collaboration, customers evaluate the service specifications, provide feedback, and help to match service features to their requirements (Chen et al., 2011; Menguc et al., 2014). Consequently, collaboration with customers creates a source of relevant knowledge through which firms can develop services that offer meaningful and useful benefits to customers. Thus,

H1b: Customer collaboration is positively related to service meaningfulness.

Supplier collaboration represents the extent to which a B2B service firm engages with its supplier to jointly develop and deliver services (Ordanini \& Parasuraman, 2011). Collaborating with suppliers is identified as the key sources of complementary knowledge beyond the organizational boundaries (Un \& Asakawa, 2015), shared learning (Agarwal \& Selen, 2009), and a key driver of service innovation (Ordanini \& Parasuraman, 2011; Storey et al., 2016). We argue that effective collaboration with suppliers increases service novelty as the knowledge share between the supplier and the service firm may result in identifying new areas for service innovation (Wang et al., 2016). The integration of knowledge collected through collaboration enables the service firm to connect diverse and new ideas to develop novel services (Agarwal \& Selen, 2009). It is also argued that when service firms collaborate with suppliers, the potential of generative learning and fundamental changes is likely to be higher than in the absence of such collaboration (Ordanini \& Parasuraman, 2011; Wang et al., 2016). Because suppliers may possess different interpretations and understanding of the market, they may provide new and diverse information, trigger changes, and challenge the existing assumptions regarding market needs (Ordanini \& Parasuraman, 2011). Therefore, supplier 
collaboration helps service firms to possess diverse perspectives and ideas to develop novel services. Thus,

H2a: Supplier collaboration is positively related to service novelty.

It is argued that a firm and its suppliers commonly operate in the related market domains, and supplier collaboration is built on long-term commitment and common objectives (Menguc et al., 2014; Un \& Asakawa, 2015). Through long-term collaboration, the firm and the supplier work closely to improve their efficiency, minimize design errors, and identify the service development requirements (Ordanini \& Parasuraman, 2011). Supplier collaboration also involves activities such as joint market sensing that helps the service firm and its suppliers gain different and deeper perceptions of customers' expectations (Wang et al., 2016). When a service firm and its suppliers integrate diverse views of customer needs, they are more likely to undertake joint activities to address customer requirements (Un \& Asakawa, 2015). A deeper understanding of customer needs helps to develop service features that match customer needs and provide meaningful benefits to customers (Wang et al., 2016). Thus,

H2b: Supplier collaboration is positively related to service meaningfulness.

\subsection{The moderation effect of exploratory learning}

Exploratory learning represents gathering and using knowledge that are new to the firm for the purpose of experimentation and creation of new processes and services (Wang et al., 2016; Mazloomi et al., 2017). We argue that the level of exploratory learning will influence B2B service firm's behavior when collaborating with customers and suppliers in their effort to drive service novelty. Exploratory learning encourages B2B service firms to dedicate effort to discovery and experimentation of novel service ideas (Mazloomi et al., 2017). In this sense, a B2B service firm may pick and use new knowledge elements through interaction with their partners to develop new processes and skills to create novel services (Perks et al., 2012; 
Mazloomi et al., 2017). This learning approach challenges the existing processes and understanding of customer needs, which in turn can lead to re-evaluation and recombination of the internal knowledge base and a better ability to offer novel services. Given that customers and suppliers may share knowledge that differs from knowledge exist inside a firm, the firm's openness and the capacity to explore diverse knowledge facilitates the adoption of new ideas and skills to develop novel service (Mazloomi et al., 2017). Furthermore, it is expected that the service firm's openness to diverse ideas encourages customers and suppliers to share more information and work closely to create novel services. Therefore, exploratory learning increases the synergy between the service firm and its suppliers and customers to jointly develop novel services. Thus,

H3: Exploratory learning positively moderates the effect of (a) customer collaboration and (b) supplier collaboration on service novelty.

Regarding the moderation effect of exploratory learning on the relationship between interfirm collaboration and service meaningfulness, we argue that emphasizing on exploratory learning in collaboration with customers and suppliers does not come without cost. Exploring diverse knowledge from partners lead to interfirm learning, but the integration and utilization of those knowledge elements involve considerable efforts and resource investment (Rothaermel \& Alexandre 2009; Mazloomi et al., 2017). In this sense, firms may acquire new knowledge and ideas without possessing the necessary competence to translate them into useful benefits for customers (Rothaermel \& Alexandre 2009). In particular, the firm's attempts to practically experiment new ideas are commonly regarded as "perpetual beta" that needs further improvements and fine-tuning (Perks et al., 2012). Therefore, the substantial efforts required to explore and integrate diverse external knowledge may adversely affect the collaboration with customers and suppliers in developing meaningful services. Thus, 
H4: Exploratory learning negatively moderates the effect of (a) customer collaboration and (b) supplier collaboration on service meaningfulness.

\subsection{The moderation effect of cross-functional collaboration (CFC)}

CFC refers to the degree of cooperation and contribution of employees to accomplish common objectives ( $\mathrm{Li}$ et al., 2007). The literature on KBV has advocated CFC as a knowledge management mechanism that facilitates the acquisition and distribution of knowledge across different functional areas (Ordanini \& Parasuraman, 2011; Melton \& Hartline, 2013). We argue that analyzing and interpreting knowledge acquired from business partners can be challenging because a partner and the service provider may operate in different industries and exchanged information will be outside of the service employee's expertise. Through CFC, employees discuss and share their different viewpoints of an issue (e.g., new ideas from a supplier) to achieve an advanced understanding (Melton \& Hartline, 2013). CFC elevates the firm's knowledge base diversity when employees share and integrate different pieces of knowledge emanating from business partners to develop new services (Ordanini \& Parasuraman, 2011). Therefore, CFC represents a mechanism that extends the service firm's capacity to effectively collaborate with customers and suppliers and comprehend knowledge and new ideas collected from them to develop novel services. Thus,

H5: CFC positively moderates the effect of (a) customer collaboration and (b) supplier collaboration on service novelty.

When employees collaborate as a cohesive goal-oriented team, they will better understand the firm's limitations to address customer requirements and gaps in the service provision process (Melton \& Hartline, 2013). Through CFC, employees may share information about the business partner's capabilities and how involving suppliers and customers in the service provision helps to overcome identified limitations and gaps. Therefore, CFC elevates a 
firm's understanding of how collaborating with suppliers and customers will complement its capacity to minimize gaps in the service provision process and effectively address customer needs. Furthermore, it is argued that employees across the service firm may have different levels of expertise and skills to identify the customer's complex requirements (Ordanini \& Parasuraman, 2011). When employees engage in CFC activities, they will gain the equivalent understanding of knowledge elements acquired from business partners and effectively deploy those elements to develop services that fit customer needs and provide meaningful benefits to customers. Thus,

H6: CFC positively moderates the effect of (a) customer collaboration and (b) supplier collaboration on service meaningfulness.

\subsection{The moderation effect of knowledge tacitness}

Tacit knowledge is defined as the knowledge that is complex, hard to transfer, and difficult to codify in written documents (De Luca \& Atuahene-Gima, 2007; Richtner et al., 2014). Following Storey et al. (2016), we view B2B services as tacit services, where knowledge sharing and interfirm collaborations are prone to significant coordination efforts. We argue the knowledge tacitness may negatively influence the business partner's capacity to communicate, share, learn, and use the knowledge (Storey et al., 2016). This negative effect happens because understanding and codifying tacit knowledge is difficult and depends on the individual cognition and accumulated knowledge and expertise (Kim et al., 2013). The higher levels of expertise involved in B2B services makes it harder for a customer and/or supplier to understand their role and expectations in the service development process.

More importantly, a B2B service firm and its customers and suppliers may operate in different industries and do not have the same accumulated knowledge and expertise. In this sense, knowledge tacitness associated with the B2B service firm prevents effective knowledge sharing and communicating among business partners with different operational backgrounds. 
Therefore, the service firm should place additional coordination effort to avoid confusion among partners, which may leave less time for service employees to focus on developing novel service ideas (Brivot, 2011). Furthermore, difficulties involved in sharing tacit knowledge decrease the business partners' capacity to understand the objectives and expectations of their participation during service development. Consequently, customers and suppliers may provide less relevant or inaccurate information required to develop services that effectively meet customer needs. Therefore, knowledge tacitness of B2B service provider negatively influences the contributions of customer and supplier collaboration on service novelty and meaningfulness. Thus,

H7: Knowledge tacitness negatively moderates the effect of (a) customer collaboration and (b) supplier collaboration on service novelty.

H8: Knowledge tacitness negatively moderates the effect of (a) customer collaboration and (b) supplier collaboration on service meaningfulness.

\section{Research method}

\subsection{Data collection}

We collected primary data using a multiple-informant questionnaire design from two managers within B2B service firms in Iran. Multiple-informant design is an effective approach to reduce sample bias problems involved in surveying single informants (Kim et al., 2013; Podsakoff et al., 2003). The original questionnaire was created in English and translated into Persian using the back-translation procedure to ensure translation equivalence (Wei et al., 2014). We used face-to-face interviews to pretest the questionnaires with a sample of managers to ensure the readability and comprehensibility of translated questionnaires. After a few minor changes in wording, we contacted 400 B2B service firms listed in a B2B services business directory, Industrial Management Institute in Iran. We invited B2B service firms in three sectors of engineering consulting, management and marketing consulting, and financial investment 
services. These B2B service sectors have been characterized as tacit knowledge service firms that offer services through collaboration with their suppliers and customers (Zaefarian et al, 2013; Bello et al., 2016). Following Ramani and Kumar (2008), we employed diverse B2B service sectors to promote generalizability of findings. We assessed all potential respondents through initial contact and ensured they have introduced at least one new service over previous three years. From the contacted firms, 350 firms that met the criteria and accepted to participate in this study. Finally, we collected 183 usable survey packages (containing two questionnaires). We examined the non-response bias by comparing the groups of participating and nonparticipating firms based on firm age and size. The results indicate no significant difference between two groups, thus non-response bias was not a concern.

Following Kim et al. (2013), we employed a two-stage sampling method to identify the appropriate respondents. First, we contacted a senior manager $(60 \% \mathrm{CEO}, 13 \%$ managing director, $27 \%$ vice president) to answer questions related to the customer collaboration, supplier collaboration, exploratory learning, CFC, knowledge tacitness, and control variables. Respondents were instructed to answer questions with respect to a new service their firm introduced over previous three years. Then, the senior manager was asked to introduce a middle-manager (55\% project manager, $41 \%$ marketing manager, and $4 \%$ others) to answer questions related to novelty and meaningfulness of selected new service. In the cover letter accompanied with the questionnaire, informants were guaranteed confidentiality and anonymity to reduce social desirability (Podsakoff et al., 2003). Overall, 45\% of studied firms were engineering consulting, 39\% were management and marketing consulting, and $16 \%$ were financial investment services. Most of the studied firms were medium-small sized services with the average size of less than 100 full-time employees and an average age of 8 years. $58 \%$ of the respondents had over 10 years working experience; $40 \%$ had between 5 and 10 years, and $2 \%$ had less than 5 years. 


\subsection{Measures}

We measured all constructs using established items from the literature on seven-point scales of " $1=$ not at all" to " $7=$ very much so". We adopted four items from Ordanini et al. (2014) to measure each of service novelty and meaningfulness. The wording of these items was slightly revised to suit the context of the study (see comparable measures by Stock et al., 2015). We used five items from Li and Atuahene-Gima (2001) to measure supplier collaboration. Customer collaboration was measured using four items borrowed from Heirati et al. (2016). CFC was measured employing four items from Li et al. (2007). Knowledge tacitness was measured using four items borrowed from De Luca and Atuahene-Gima (2007). We measured exploratory learning using four items from Wei et al. (2014). Following Zaefarian et al. (2013) and Un \& Asakawa (2015), we measured firm size (the logarithm number of employees), firm age (years of operation), and service industry sector as control variables. All measures are outlined in Appendix I.

\subsection{Analysis}

We employed partial least squares (PLS) structural equation modeling to assess data validity and test hypotheses. We employed PLS for a number of reasons. Recent applications of PLS is found in the industrial marketing and supply chain management literature (Reinartz et al., 2009; Hair et al., 2011). PLS as a variance-based structural equation technique is particularly suitable for predictive purposes when the theory is still under development (Hair et al., 2011). PLS is suitable for testing complex models (like our model with many moderation effects) with relatively small samples (Reinartz et al., 2009). Following Hair et al. (2011), we tested our model using path-weighting scheme with a maximum of 300 iterations and the bootstrapping procedure of 5000 resamples.

We assessed the measurement model before examining the structural model. As shown in Appendix I, all measures exceed threshold values of 0.50 (Hair et al., 2011). We examined 
average variance extracted (AVE) and composite reliability (CR) to test convergent and discriminant validity. Table 1 indicates that all constructs had acceptable composite reliability $(\mathrm{CR}>0.70)$ and AVE $(\mathrm{AVE}>0.50)$. We examined discriminant validity using the Fornell and Larcker (1981) criterion and calculated the square root of AVEs for all constructs. As shown in Table 1, the square root of AVEs were greater than all individual correlations, indicating discriminant validity.

We examined the threat of common method bias using the marker variable (MV) technique (Lindell \& Whitney, 2001). We used the respondents' knowledgeability to answer questions as MV, which is theoretically unrelated to others variables in the model. After the adjustments of coefficients using the lowest positive coefficient value $\left(r_{m}=0.02\right)$, Table 1 indicates that the MV adjustment did not significantly change any correlation coefficient, suggesting no evidence of common method bias.

-Table 1 here-

\subsection{Results}

Table 2 summarizes the results of hypotheses. Hypotheses 1 and 2 examined the effect of customer and supplier collaboration on service novelty and meaningfulness. The results support $\mathrm{H} 1 \mathrm{a}$ and $\mathrm{H} 1 \mathrm{~b}$ as customer collaboration positively influenced novelty $(\beta=0.28, p<0.01)$ and meaningfulness $(\beta=0.18, p<0.05)$. Results also support $\mathrm{H} 2 \mathrm{~b}$ as supplier collaboration positively influenced meaningfulness $(\beta=0.17, p<0.05)$. However, supplier collaboration did not significantly affect novelty $(\beta=0.11, \mathrm{~ns})$, rejecting H2a.

Hypotheses 3 to 8 examined the moderation effects of exploratory learning, CFC, and knowledge tacitness on the effects of customer collaboration and supplier collaboration on service novelty and meaningfulness. Following Aiken et al. (1991), we performed the meancentering procedure to minimize multicollinearity in the moderation effects. We also performed 
single slope analysis and plotted moderation effects in Figure 2. The results in Table 2 and Figure 2 support $\mathrm{H} 3 \mathrm{a}$ and $\mathrm{H} 3 \mathrm{~b}$ as exploratory learning significantly amplified the effects of customer collaboration $(\beta=0.27, p<0.01)$ and supplier collaboration $(\beta=0.13, p<0.05)$ on novelty. The single slope analysis reveals the relationships of customer collaboration - novelty $\left(\beta_{\text {High }}=0.54, \beta_{\text {Low }}=0.01\right)$ and supplier collaboration - novelty $\left(\beta_{\text {High }}=0.24, \beta_{\text {Low }}=-0.02\right)$ are stronger when the level of exploratory learning is high.

$\mathrm{H} 4 \mathrm{a}$ and $\mathrm{H} 4 \mathrm{~b}$ are supported as exploratory learning negatively moderated the effects of customer collaboration $(\beta=-0.14, p<0.10)$ and supplier collaboration $(\beta=-0.14, p<0.05)$ on meaningfulness. The single slope analysis shows the relationships of customer collaborationmeaningfulness $\left(\beta_{\mathrm{High}}=0.04, \quad \beta_{\mathrm{Low}}=0.32\right)$ and supplier collaboration - meaningfulness $\left(\beta_{\mathrm{High}}=0.03, \beta_{\mathrm{Low}}=0.31\right)$ are weaker when the level of exploratory learning is high.

The findings also support H5a by indicating that CFC positively moderated the effect of customer collaboration on novelty $(\beta=0.19, p<0.05)$. However, results do not support the moderation effects of CFC on the relationships between supplier collaboration and novelty $(\beta=$ $-0.06, \mathrm{~ns})$, rejecting H5b. The results also do not support the moderation effects of CFC on the relationships between customer collaboration and meaningfulness $(\beta=0.13, \mathrm{~ns})$, rejecting H6a. H6b is supported as CFC positively moderated the effect of supplier collaboration on meaningfulness $(\beta=0.27, p<0.01)$. The single slope analysis indicates the relationships of customer collaboration - novelty $\left(\beta_{\mathrm{High}}=0.48, \beta_{\mathrm{Low}}=0.07\right)$ and supplier collaboration meaningfulness $\left(\beta_{\mathrm{High}}=0.46, \beta_{\mathrm{Low}}=-0.12\right)$ are stronger when the level of $\mathrm{CFC}$ is high.

The findings support $\mathrm{H} 7 \mathrm{a}$ as knowledge tacitness negatively moderated the effect of customer collaboration on novelty $(\beta=-0.15, p<0.05)$. However, the results do not support the moderation effects of knowledge tacitness on the relationships between supplier collaboration and novelty $(\beta=-0.10, \mathrm{~ns})$, rejecting $\mathrm{H} 7 \mathrm{~b}$. The findings do not support the moderation effects of knowledge tacitness on the relationships between customer collaboration and 
meaningfulness $(\beta=0.08$, ns), rejecting $\mathrm{H} 8 \mathrm{a} . \mathrm{H} 8 \mathrm{~b}$ is supported as knowledge tacitness negatively moderated the relationships between supplier collaboration and meaningfulness ( $\beta=$ $-0.25, p<0.01)$. The single slope analysis reveals the relationships of customer collaboration novelty $\left(\beta_{\mathrm{High}}=0.11, \beta_{\mathrm{Low}}=0.44\right)$ and supplier collaboration - meaningfulness $\left(\beta_{\mathrm{High}}=-0.10\right.$, $\left.\beta_{\text {Low }}=0.45\right)$ are weaker when the level of knowledge tacitness is high.

-Table 2 here-

-Figure 2 here-

\section{Discussion}

In this study, we set out to better understand the mechanisms that a B2B service firm can put in place to improve novelty and meaningfulness aspects of service innovativeness. We integrated collaboration perspective of $\mathrm{B} 2 \mathrm{~B}$ services with $\mathrm{KBV}$ to investigate the independent contributions of customer and supplier collaboration to service novelty and meaningfulness. Further, we examined contextual roles of explorative learning, CFC, and knowledge tacitness on the outcomes of customer and supplier collaboration. Our motivation was to provide a more comprehensive understanding of the conditions under which collaboration with customers and suppliers is beneficial to drive novelty and meaningfulness of their services. Our findings offer several theoretical and managerial implications.

\subsection{Theoretical implications}

First, our results extend the work of Ordanini and Parasuraman (2011) regarding the effects of customer and supplier collaboration on service innovation outcomes. We provide an alternate perspective by examining the impacts of these collaborations on different aspects of service innovativeness, novelty and meaningfulness. Further, we extend their work by examining contextual factors that alter the effect of collaboration on service novelty and meaningfulness. Our findings support that customer collaboration enhances both service 
novelty and meaningfulness. These findings are in line with the extant research that view customer collaboration as the source of new service ideas (Perks et al., 2012). However, our results to some extent contradict the work of Ordanini and Parasuraman (2011) who show that customer collaboration drive innovation volume, but has no effect on developing breakthrough new services in the context of hotel industry. The reason for these contradictory results may be found in the nature of our sample and consumers in the hotel industry. Hotel consumers may hold a short view of the relationship with the service provider and only focus on their current needs. However, business customers hold a long-term view of business relationships and are more concerned about the future of their own businesses. In this sense, business customers are motivated to actively contribute to the service development process, jointly create novel ideas, and match service specifications to their needs.

We also found supplier collaboration drives meaningfulness, however; it has no significant influence on service novelty. These findings contradict the work of Ordanini and Parasuraman (2011) who show supplier collaboration drives radical service innovation in the hotel industry. We believe the nature of supplier collaboration in B2B services differs from less complex and standardized consumer services, such as hotel industry. In B2B relationships, suppliers may avoid sharing radically new ideas and discourage service firms from developing substantially novel service features to protect their existing investments such as their employee training and installation techniques. More importantly, many B2B service firms may limit supplier involvement at different stages of service design to protect their know-how and minimize knowledge leak. knowledge leak is more critical for B2B services compared to the other industries, because of lack of patent. Suppliers who learn know-how to develop comparable services may become future competitors or share it with other firms in the market. These potential drawbacks of supplier collaboration and the service firm's protective behavior may offset the potential contribution of supplier collaboration to service novelty. 
Second, our study extends the existing research that suggests the exploratory learning influences the outcomes of a firm's interorganizational relationships (Rothaermel \& Deeds, 2004; Mazloomi et al., 2017). Our results contribute to the literature by showing exploratory learning moderates the effect of customer and supplier collaboration on novelty and meaningfulness in different ways. In particular, the results reveal that exploratory learning positively moderates the effects of customer and supplier collaboration on service novelty, while it negatively moderates the effects of customer and supplier collaboration on service meaningfulness. B2B service firms with greater levels of exploratory learning are more likely to pick and collect knowledge elements that facilitate the creation of novel service ideas at the expense of paying less attention to the efficiency of their existing processes and services. In this sense, B2B service firms may become less attentive to the customer's signals about their current needs. The lack of understanding of customer needs dampens the firm's capacity to ensure the meaningfulness of their services. The negative moderation effect of exploratory learning is consistent with Rothaermel and Alexandre (2009) who shows that the firm's external focus - collecting knowledge from partners - in exploration has a nonlinear effect on innovativeness. We extend their work by showing that exploratory learning plays different roles when service firms collaborate with customers and suppliers to drive service novelty and meaningfulness.

Third, the results advance our understanding of the role of CFC. Specifically, we advance prior research that shows employee collaboration as the key to integrating and activating knowledge in the context of B2B services (Melton \& Hartline, 2013; Ordanini \& Parasuraman, 2011). Our study shows CFC plays an important role in enhancing the capacity to leverage the benefits of customer collaboration to drive service novelty. However, we found that this role is less relevant in driving service meaningfulness when collaborating with customers. The underlying reason could be that customers may share complex problems and, 
new knowledge during service development and delivery process. In this sense, employees need to integrate their interpretations of information shared by customers to reach a common understanding of what the new knowledge means (see Li et al., 2007; Melton \& Hartline, 2013). When receiving less complex information that helps to improve the quality and usefulness of existing services, employees may simply share those information through documented reports and a high level of CFC does not add any substantial value to address customer needs. In contrast, the results show that CFC helps to leverage the benefits of supplier collaboration to drive service meaningfulness rather than novelty. As noted earlier, we believe the protective behavior of the B2B service firms regarding the critical knowledge leak to suppliers will neutralize the potential effect of supplier collaboration on novelty (see Heirati et al., 2016).

Fourth, our study advances the literature by investigating the contextual role of knowledge tacitness as an inherent characteristic of B2B services. We examined the negative impact of knowledge tacitness on the effectiveness of customer and supplier collaboration. The results partially support our theory by revealing that knowledge tacitness negatively moderates the relationships between customer collaboration - service novelty and supplier collaboration - service meaningfulness. Our findings support the argument raised by Un \& Asakawa (2015) who believe that firms should facilitate conversion of tacit knowledge into explicit knowledge to effectively collaborate with business partners. We conclude that B2B service firms should assess the level of their knowledge tacitness and the effort required to communicate relevant knowledge elements to their partners before engaging in a high level of collaboration with customers and suppliers.

\subsection{Managerial implications}

This research holds specific implications for managers because collaboration is often formed with the purpose of sharing, coordinating information and specialized knowledge that are useful in innovation processes. Our findings instruct managers to set clear objectives for 
collaboration with customers and suppliers to develop innovative services. Our results suggest managers, who wish to develop novel services, to invest more on collaboration with customers. However, if service meaningfulness is the main objective, managers are better off to invest in collaboration with suppliers.

Our study introduces exploratory learning and $\mathrm{CFC}$ as the mechanisms that managers can undertake to enhance the effect of collaboration on service innovativeness. We again emphasize setting objectives for service innovation. If the primary objective is service novelty, managers need to engage in exploratory learning to leverage the effect of collaboration with customers and suppliers. Utilizing external knowledge from business partners requires an explorative mindset because such a mindset persuades flexibility to adopt alternative ideas and challenge existing internal knowledge. This exploratory mindset is encouraged by many firms that allow employees to use one-fifth of their time to learn new skills and look for new opportunities outside the organizational boundaries. We also advise managers to be aware of the downside of exploratory learning when collaborating with customers and suppliers. To minimize this downside, managers can develop multidisciplinary teams (e.g., technical, project management) within a service project to ensure that knowledge coming from customers and suppliers is interpreted from different perspectives. This approach helps to ensure that firms collect relevant external knowledge elements to develop novel and meaningful services.

Our results also indicate that when the primary objective is service meaningfulness, managers should encourage CFC to maximize the benefits gained from the supplier collaboration. Formal processes such as frequent meetings and teamwork can facilitate knowledge sharing among employees. Further, informal mechanisms such as social activities and incentives can complement formal CFC mechanisms to ensure all employees focus on common objectives. Lastly, we advise managers about the negative effect of knowledge tacitness when collaborating with customers and suppliers throughout service innovativeness 
process. We suggest managers encourage employees to routinize the organizational processes, communicate with business partners as simple as possible, and avoid using very technical expression and explanations. Managers should understand that their suppliers and customers may lack expertise knowledge in specific areas, thus documented instructions and clear guideline are required to facilitate collaboration. Managers should assess the level of knowledge tacitness resides in their firm and the effort required to clearly communicate relevant knowledge elements to their partners before engaging in collaboration.

\subsection{Limitations and further research}

This study is limited to a certain extent because of employing the cross-sectional data and potential risk of causal inferences. First, future research can consider the longitudinal approach to evaluating the role of supplier and customer collaboration over different stages of service development and delivery. Second, our data is based on B2B service firms; thus, the results might be different in $\mathrm{B} 2 \mathrm{C}$ and not-for-profit service sectors. Future research can replicate this study in other service sectors to strengthen the generalizability of our findings. Third, it is plausible that organizational factors such as cultural norms, service climate, and leadership approach influence interfirm collaboration. Future studies can extend our study by investigating these factors to advance our understanding of boundary conditions that facilitate interfirm collaboration. Fourth, we measured the contextual role of exploratory learning, CFC, and knowledge tacitness from the focal service firm's perspective. However, the nature of these factors may vary across supplier and customer firms. Therefore, a potential avenue for future research is to investigate how these knowledge management factors across the focal service firm, the customer, and the supplier influence the outcomes of interfirm collaboration. 


\section{References}

Agarwal, R., \& Selen, W. (2009). Dynamic capability building in service value networks for achieving service innovation. Decision Sciences, 40(3), 431-475.

Aiken, L., West, S., \& Reno, R. (1991). Multiple regression: Testing and interpreting interactions: Sage.

Alam, I. (2002). An exploratory investigation of user involvement in new service development. Journal of the Academy of Marketing Science, 30(3), 250-261.

Baker, W., Grinstein, A., \& Harmancioglu, N. (2016). Whose innovation performance benefits more from external networks: entrepreneurial or conservative firms? Journal of Product Innovation Management, 33(1), 104-120.

Bello, D., Radulovich, L., Javalgi, R., Scherer, R., \& Taylor, J. (2016). Performance of professional service firms from emerging markets: Role of innovative services and firm capabilities. Journal of World Business, 51(3), 413-424.

Blazevic, V., \& Lievens, A. (2008). Managing innovation through customer coproduced knowledge in electronic services: An exploratory study. Journal of the Academy of Marketing Science, 36(1), 138-151.

Brivot, M. (2011). Controls of knowledge production, sharing and use in bureaucratized professional service firms. Organization Studies, 32(4), 489-508.

Carbonell, P., Rodríguez-Escudero, A., \& Pujari, D. (2009). Customer Involvement in New Service Development: An Examination of Antecedents and Outcomes. Journal of Product Innovation Management, 26(5), 536-550.

Chen, J., Tsou, H., \& Ching, R. (2011). Co-production and its effects on service innovation. Industrial Marketing Management, 40(8), 1331-1346.

De Luca, L., \& Atuahene-Gima, K. (2007). Market knowledge dimensions and cross-functional collaboration: Examining the different routes to product innovation performance. Journal of Marketing, 71(1), 95-112.

Dotzel, T., Shankar, V., \& Berry, L. (2013). Service innovativeness and firm value. Journal of Marketing Research, 50(2), 259-276.

EUROSTAT. (2008). Science, Technology and Innovation in Europe. Retrieved from Luxembourg:

Franke, N., Schreier, M., \& Kaiser, U. (2010). The "I designed it myself" effect in mass customization. Management Science, 56(1), 125-140. 
Garcia, R., \& Calantone, R. (2002). A critical look at technological innovation typology and innovativeness terminology: a literature review. Journal of Product Innovation Management, 19(2), 110-132.

Grant, R. (1996). Toward a knowledge-based theory of the firm. Strategic Management Journal, 17(S2), 109-122.

Hair, J., Sarstedt, M., Ringle, C., \& Mena, J. (2011). An assessment of the use of partial least squares structural equation modeling in marketing research. Journal of the Academy of Marketing Science, 40(3), 414-433.

Heirati, N., O'Cass, A., Schoefer, K., \& Siahtiri, V. (2016). Do professional service firms benefit from customer and supplier collaborations in competitive, turbulent environments? Industrial Marketing Management, 55(5), 50-58.

Huang, M., \& Rust, R. (2013). IT-related service: A multidisciplinary perspective. Journal of Service Research, 16(3), 251-258.

Kaiser, S., \& Ringlstetter, M. (2010). Strategic management of professional service firms: Theory and practice: Springer Science \& Business Media.

Kim, N., Im, S., \& Slater, S. (2013). Impact of knowledge type and strategic orientation on new product creativity and advantage in high-technology firms. Journal of Product Innovation Management, 30(1), 136-153.

Li, H., \& Atuahene-Gima, K. (2001). Product innovation strategy and the performance of new technology ventures in China. Academy of Management Journal, 44(6), 1123-1134.

Li, H., Bingham, J., \& Umphress, E. (2007). Fairness from the Top: Perceived Procedural Justice and Collaborative Problem Solving in New Product Development. Organization Science, 18(2), 200-216.

Lindell, M., \& Whitney, D. (2001). Accounting for common method variance in cross-sectional research designs. Journal of Applied Psychology, 86(1), 114-121.

Mahr, D., Lievens, A., \& Blazevic, V. (2014). The value of customer cocreated knowledge during the innovation process. Journal of Product Innovation Management, 31(3), 599615.

March, J. (1991). Exploration and exploitation in organizational learning. Organization Science, 2(1), 71-87.

Mazloomi, H., Jolly, D., \& Morel, L. (2017). The effect of learning approaches on the utilization of external knowledge in strategic alliances. Industrial Marketing Management, 63, 92-104. 
Melton, H., \& Hartline, M. (2010). Customer and frontline employee influence on new service development performance. Journal of Service Research, 13(4), 411-425.

Melton, H., \& Hartline, M. (2013). Employee Collaboration, Learning Orientation, and New Service Development Performance. Journal of Service Research, 16(1), 67-81.

Menguc, B., Auh, S., \& Yannopoulos, P. (2014). Customer and Supplier Involvement in Design: The Moderating Role of Incremental and Radical Innovation Capability. Journal of Product Innovation Management, 31(2), 313-328.

Mina, A., Bascavusoglu-Moreau, E., \& Hughes, A. (2014). Open service innovation and the firm's search for external knowledge. Research Policy, 43(5), 853-866.

Ordanini, A., \& Parasuraman, A. (2011). Service innovation viewed through a servicedominant logic lens: A conceptual framework and empirical analysis. Journal of Service Research, 14(1), 3-23.

Ordanini, A., Parasuraman, A., \& Rubera, G. (2014). When the recipe is more important than the ingredients a Qualitative Comparative Analysis (QCA) of service innovation configurations. Journal of Service Research, 17(2), 134-149.

Ostrom, A., Parasuraman, A., Bowen, D., Patricio, L., \& Voss, C. (2015). Service research priorities in a rapidly changing context. Journal of Service Research, 18(2), 127-159.

Perks, H., Gruber, T., \& Edvardsson, B. (2012). Co-creation in Radical Service Innovation: A Systematic Analysis of Microlevel Processes. Journal of Product Innovation Management, 29(6), 935-951.

Podsakoff, P., MacKenzie, S., Lee, J., \& Podsakoff, N. (2003). Common method bias in behavioral research: A critical review of the literature and recommended remedies. Journal of Applied Psychology, 88(5), 879-903.

Prior, D. (2013). Supplier representative activities and customer perceived value in complex industrial solutions. Industrial Marketing Management, 42(8), 1192-1201.

Ramani, G., \& Kumar, V. (2008). Interaction orientation and firm performance. Journal of Marketing, 72(1), 27-45.

Reinartz, W., Haenlein, M., \& Henseler, J. (2009). An empirical comparison of the efficacy of covariance-based and variance-based SEM. International Journal of Research in Marketing, 26, 332-344.

Richtner, A., Ahlstrom, P., \& Goffin, K. (2014). "Squeezing R\&D”: A Study of Organizational Slack and Knowledge Creation in NPD, Using the SECI Model. Journal of Product Innovation Management, 31(6), 1268-1290. 
Rothaermel, F., \& Deeds, D. (2004). Exploration and exploitation alliances in biotechnology: A system of new product development. Strategic Management Journal, 25(3), 201-221.

Rothaermel, F., \& Alexandre, M. (2009). Ambidexterity in technology sourcing: The moderating role of absorptive capacity. Organization Science, 20(4), 759-780.

Schumpeter, J. (1934). The theory of economic development: An inquiry into profits, capital, credit, interest, and the business cycle (Vol. 55): Transaction publishers.

Siahtiri, V. (2017). Does cooperating with customers support the financial performance of business-to-business professional service firms?. Journal of Service Theory and Practice, 27(3), 547-568.

Snyder, H., Witell, L., Gustafsson, A., Fombelle, P., \& Kristensson, P. (2016). Identifying categories of service innovation: A review and synthesis of the literature. Journal of Business Research, 69(7), 2401-2408.

Stewart, D. W., \& Zinkhan, G. M. (2006). From the Editors: Enhancing marketing theory in academic research. Journal of the Academy of Marketing Science, 34, 477-480.

Stock, R., \& Zacharias, N. (2013). Two sides of the same coin: How do different dimensions of product program innovativeness affect customer loyalty?. Journal of Product Innovation Management, 30(3), 516-532.

Stock, R., Oliveira, P., \& Hippel, E. (2015). Impacts of Hedonic and Utilitarian User Motives on the Innovativeness of User-Developed Solutions. Journal of Product Innovation Management, 32(3), 389-403.

Storey, C., \& Kahn, K. (2010). The Role of Knowledge Management Strategies and Task Knowledge in Stimulating Service Innovation. Journal of Service Research, 13(4), 397410.

Storey, C., Cankurtaran, P., Papastathopoulou, P., \& Hultink, E. (2016). Success Factors for Service Innovation: A Meta-Analysis. Journal of Product Innovation Management, $33(5), 527-548$.

Toivonen, M., \& Tuominen, T. (2009). Emergence of innovations in services. The Service Industries Journal, 29(7), 887-902.

Un, C., \& Asakawa, K. (2015). Types of R\&D collaborations and process innovation: The benefit of collaborating upstream in the knowledge chain. Journal of Product Innovation Management, 32(1), 138-153.

Voss, G., \& Voss, Z. (2013). Strategic ambidexterity in small and medium-sized enterprises: Implementing exploration and exploitation in product and market domains. Organization Science, 24(5), 1459 - 1477. 
Wang, J., Li, J., \& Chang, J. (2016). Product co-development in an emerging market: The role of buyer-supplier compatibility and institutional environment. Journal of Operations Management, 46, 69-83.

Wei, Z., Yi, Y., \& Guo, H. (2014). Organizational learning ambidexterity, strategic flexibility, and new product development. Journal of Product Innovation Management, 31(4), 832847.

Zaefarian, G., Henneberg, S., \& Naudé, P. (2013). Assessing the strategic fit between business strategies and business relationships in knowledge-intensive business services. Industrial Marketing Management, 42(2), 260-272. 
Fig. 1 Theoretical framework

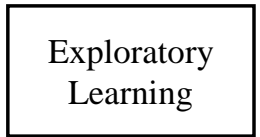

$\mathrm{H} 3-\mathrm{H} 4$ \begin{tabular}{|c|}
\hline Cross-Functional \\
Collaboration
\end{tabular}

$\mathrm{H} 5-\mathrm{H} 6$

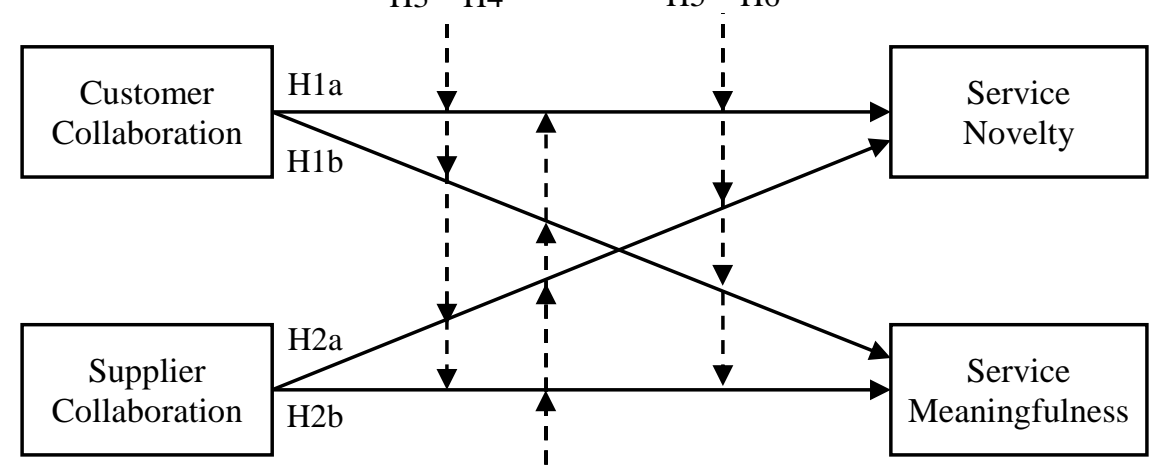

$\mathrm{H} 7-\mathrm{H} 8$

Knowledge

Tacitness 
Fig. 2 The interaction plots

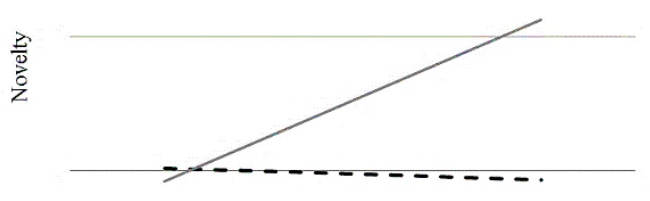

Low CC

- - Low Exploratory Learning — High Exploratory Learning

$\mathrm{H} 4 \mathrm{a}$

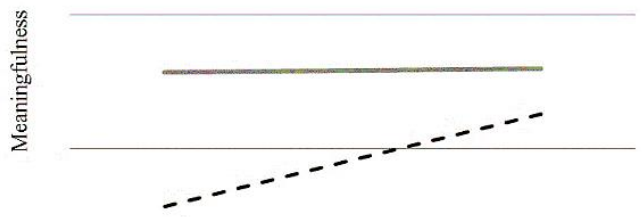

Low CC High CC

- - Low Exploratory Learning — High Exploratory Learning

$\mathrm{H} 5 \mathrm{a}$

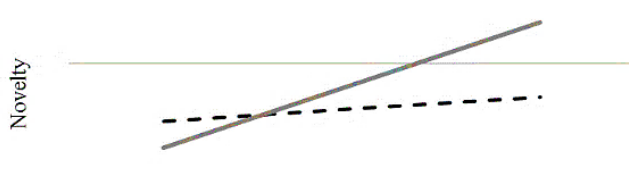

Low CC
\begin{tabular}{rr}
\hline-- Low $\mathrm{CFC}-$ High CFC \\
H7a
\end{tabular}

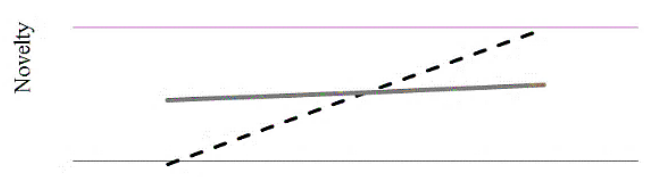

Low CC High CC

- - Low Knowledge Tacitness $\longrightarrow$ High Knowledge Tacitness

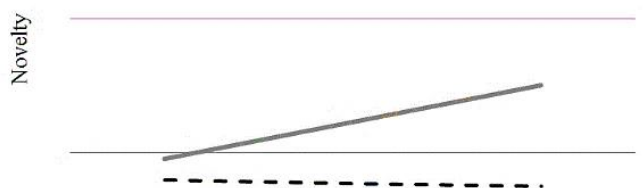

Low SC

High SC

- - Low Exploratory Learning — High Exploratory Learning

$\mathrm{H} 4 \mathrm{~b}$

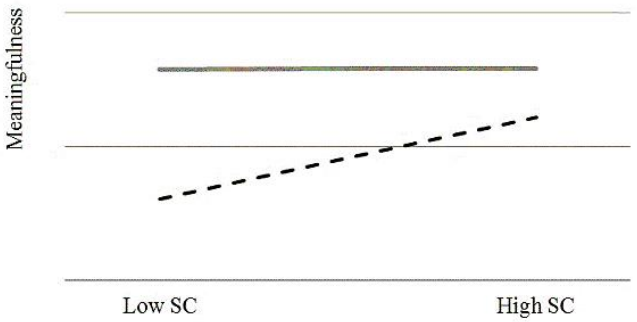

- - Low Exploratory Learning — High Exploratory Learning

H6b

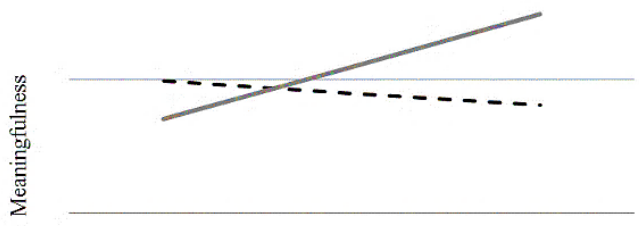

$$
\begin{array}{lr}
\text { Low SC } & \text { High SC } \\
\hline-- \text { Low CFC } & - \text { High CFC }
\end{array}
$$

$\mathrm{H} 8 \mathrm{~b}$

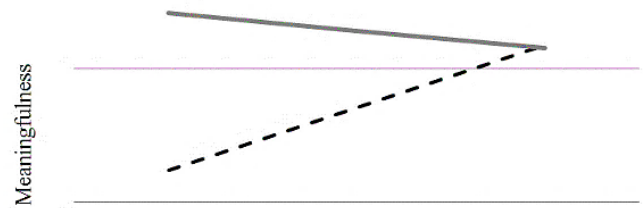

Low SC

High SC

- - Low Knowledge Tacitness — High Knowledge Tacitness 
Table 1 Correlation matrix

\begin{tabular}{lcccccccccc}
\hline & $\mathbf{1}$ & $\mathbf{2}$ & $\mathbf{3}$ & $\mathbf{4}$ & $\mathbf{5}$ & $\mathbf{6}$ & $\mathbf{7}$ & $\mathbf{8}$ & $\mathbf{9}$ & $\mathbf{1 0}$ \\
\hline $\mathbf{1}$ Customer collaboration & & 0.12 & $0.46^{* *}$ & -0.03 & $0.39^{* *}$ & $0.34^{* *}$ & $0.31^{* *}$ & 0.08 & -0.03 & -0.01 \\
$\mathbf{2}$ Supplier collaboration & 0.14 & & $0.36^{* *}$ & $-0.21^{*}$ & 0.11 & $0.22^{*}$ & $0.30^{* *}$ & $-0.21^{*}$ & $-0.19^{*}$ & 0.01 \\
3 Exploratory learning & $0.47^{* *}$ & $0.37^{* *}$ & & 0.05 & $0.43^{* *}$ & $0.42^{* *}$ & $0.52^{* *}$ & -0.05 & -0.06 & -0.10 \\
$\mathbf{4}$ Knowledge tacitness & -0.01 & $-0.19^{*}$ & 0.07 & & 0.04 & -0.01 & $0.19^{*}$ & -0.03 & -0.03 & -0.01 \\
5 Cross-functional collaboration & $0.40^{* *}$ & 0.13 & $0.44^{* *}$ & 0.06 & & $0.32^{* *}$ & $0.34^{* *}$ & -0.09 & -0.08 & -0.05 \\
6 Novelty & $0.35^{* *}$ & $0.24^{* *}$ & $0.43^{* *}$ & 0.01 & $0.33^{* *}$ & & $0.30^{* *}$ & -0.11 & -0.08 & -0.04 \\
7 Meaningfulness & $0.32^{* *}$ & $0.31^{* *}$ & $0.53^{* *}$ & $0.21^{*}$ & $0.35^{* *}$ & $0.31^{* *}$ & & -0.14 & -0.11 & -0.03 \\
$\mathbf{8}$ Age & 0.10 & $-0.19^{*}$ & -0.03 & -0.01 & -0.07 & -0.09 & -0.12 & & $0.43^{* *}$ & $0.27^{* *}$ \\
9 Size & -0.01 & $-0.17^{*}$ & -0.04 & -0.01 & -0.06 & -0.06 & -0.09 & $0.44^{* *}$ & & 0.07 \\
10 Type & 0.01 & 0.03 & -0.08 & 0.01 & -0.03 & -0.02 & -0.01 & $0.28^{* *}$ & 0.09 & - \\
\hline AVE & 0.64 & 0.68 & 0.52 & 0.53 & 0.52 & 0.70 & 0.71 & - & - & - \\
CR & 0.88 & 0.91 & 0.81 & 0.82 & 0.81 & 0.90 & 0.91 & - & - & - \\
Square root of AVE & 0.80 & 0.82 & 0.72 & 0.73 & 0.72 & 0.84 & 0.84 & - & - & - \\
\hline
\end{tabular}

$*$ and ** indicate the significant level at 0.05 and 0.01 level (two tail).

Zero-order correlations are below the diagonal; adjusted correlations for potential common-method bias are above the diagonal. 
Table 2 Test of hypotheses

\begin{tabular}{|c|c|c|c|c|}
\hline \multirow[b]{2}{*}{ Customer Collaboration (CC) } & \multicolumn{2}{|c|}{ DV: Novelty } & \multicolumn{2}{|c|}{ DV: Meaningfulness } \\
\hline & $0.28^{\mathrm{a}}\left(3.24^{\mathrm{b}}\right)^{* *}$ & H1a & $0.18(2.49)^{*}$ & H1b \\
\hline Supplier Collaboration (SC) & $0.11(1.46)$ & $\mathrm{H} 2 \mathrm{a}$ & $0.17(2.08)^{*}$ & $\mathbf{H} 2 \mathbf{b}$ \\
\hline Exploratory Learning & $0.23(2.73)^{* *}$ & & $0.28(3.25)^{* *}$ & \\
\hline Cross-functional collaboration & $0.09(1.30)$ & & $0.10(1.38)$ & \\
\hline Knowledge Tacitness & $0.01(0.13)$ & & $0.24(2.80)^{* *}$ & \\
\hline \multicolumn{5}{|l|}{ Interaction effects } \\
\hline Exploratory Learning $\times \mathrm{CC}$ & $0.27(3.05)^{* *}$ & H3a & $-0.14(1.74)^{\dagger}$ & H4a \\
\hline Exploratory Learning $\times \mathrm{SC}$ & $0.13(2.10)^{*}$ & H3b & $-0.14(2.05)^{*}$ & H4b \\
\hline Cross-functional collaboration $\times \mathrm{CC}$ & $0.19(2.61)^{*}$ & H5a & $0.13(1.57)$ & H6a \\
\hline Cross-functional collaboration $\times \mathrm{SC}$ & $-0.06(0.78)$ & $\mathrm{H} 5 \mathrm{~b}$ & $0.27(2.94)^{* *}$ & H6b \\
\hline Knowledge Tacitness $\times$ CC & $-0.15(1.97)^{*}$ & H7a & $0.08(0.80)$ & $\mathrm{H} 8 \mathrm{a}$ \\
\hline Knowledge Tacitness $\times$ SC & $-0.10(1.36)$ & $\mathrm{H} 7 \mathrm{~b}$ & $-0.25(3.22)^{* *}$ & H8b \\
\hline \multicolumn{5}{|l|}{ Control variables } \\
\hline Firm age & $-0.07(0.45)$ & & $-0.10(1.50)$ & \\
\hline Firm size & $-0.01(0.24)$ & & $-0.03(0.51)$ & \\
\hline Firm type & $0.04(0.16)$ & & $-0.01(0.18)$ & \\
\hline $\mathrm{R}^{2}$ & 0.33 & & 0.49 & \\
\hline$\Delta \mathrm{R}^{2}$ & 0.09 & & 0.12 & \\
\hline $\mathrm{F}_{\text {Change }}$ & $3.29^{* *}$ & & $6.33^{* *}$ & \\
\hline
\end{tabular}

Notes: $a$ : $\beta$-coefficient, $b$ : $t$-value

†: $p<0.10, *: p<0.05, * *: p<0.01$. Supported hypotheses are bold for visual clarity. 


\section{Appendix I Constructs and variables}

Customer Collaboration - To develop and deliver the selected service, we engage in the following Loading behavior when collaborating with customers:

...work with our customers to jointly design the service that best fit the customer's conditions. $\quad .88$

$\begin{array}{ll}\text {....assist customers to define the service specifications. } & .89\end{array}$

...interact with our customers to jointly deploy (e.g., implement, operate) the service. $\quad .68$

$\begin{array}{ll}\text {...work with customers to improve the efficiency of the deployed service. } & .74\end{array}$

Supplier Collaboration - To develop and deliver the selected service, we engage in the following behavior when collaborating with suppliers:

...collaborate with other firms (e.g., suppliers, partners). $\quad .80$

$\begin{array}{lr}\text {...establish cooperative R\&D agreements with other firms. } & .67\end{array}$

$\begin{array}{ll}\text {...jointly market the service with other firms. } & .90\end{array}$

...jointly develop and implement the selected service with other firms. $\quad .85$

$\begin{array}{ll}\text {...jointly provide support for the selected service with other firms. } & .88\end{array}$

Exploratory learning - To develop and deliver the selected service, we engage in the following behavior:

...acquire knowledge to develop services that led us into new areas of learning such as new markets $\quad .78$ and technological areas.

...explore and use novel information and ideas that went beyond our current operational (e.g., market $\quad .77$ and technological) experiences.

...acquire and use new information that help us to learn new things in the service development. $\quad .74$

...collect new information and ideas that involved experimentation and high risks.

Knowledge Tacitness - Our firm's knowledge is difficult to:

...comprehensively document in manuals or reports.

$\begin{array}{ll}\text {...comprehensively understand from written documents. } & .82\end{array}$

...identify without personal experience in using them.

$\begin{array}{ll}\text {...precisely communicate through written documents. } & .78\end{array}$

Cross-functional collaboration - When developing and delivering the selected service, in our firm:

...all business functions exchange complete and accurate information with each other to resolve the $\quad .59$ specific problem(s).

$\begin{array}{lr}\text {...all business functions focus on common objective(s). } & .70\end{array}$

...all business functions engage in a collaborative effort to resolve the specific problem(s). $\quad .75$

...we frequently discuss market trends across all business functions. $\quad .81$

Service Meaningfulness - The selected service:

$\begin{array}{ll}\text {...satisfies customers' desires. } & .87\end{array}$

...is relevant to customer's expectations (e.g., exactly what customers want). 82

\begin{tabular}{lr}
...is appropriate for customer's expectations. & .91 \\
\hline
\end{tabular}

...is useful for our customers (e.g., deliver quality and performance).

Service Novelty - The selected service:

$\begin{array}{ll}\text {...is one of the first of its kind introduced into the market. } & .82\end{array}$

...is highly innovative - radically different from other services in the market. $\quad .82$

...is revolutionary - causing significant changes in the markets we operate in.

$\begin{array}{lr}\ldots \text {...is novel and exceptional. } & .86\end{array}$ 